\title{
Mathematical modelling of oxygen concentration in bovine and murine cumulus-oocyte complexes
}

\author{
A R Clark ${ }^{1}$, Y M Stokes ${ }^{1}$, M Lane ${ }^{2}$ and J G Thompson ${ }^{2}$ \\ ${ }^{1}$ School of Mathematical Sciences and ${ }^{2}$ Research Centre for Reproductive Health, Department of Obstetrics and \\ Gynaecology, The University of Adelaide, Adelaide, 5000 SA, Australia \\ Correspondence should be addressed to J G Thompson; Email: jeremy.thompson@adelaide.edu.au
}

\begin{abstract}
Immature oocytes benefit from nutrient modification of the follicular environment by the surrounding cumulus mass. However, the oxygen concentration that the oocyte may be exposed to could be lower than the antral follicular concentration due to the metabolism of surrounding cumulus cells. Using metabolic data previously determined, we have developed a mathematical model of $\mathrm{O}_{2}$ diffusion across the bovine and murine cumulus-oocyte complex. From this we have determined that across a physiological range of external $\mathrm{pO}_{2}$, less than $0.25 \%$ and $0.5 \% \mathrm{O}_{2}$ is removed by cumulus cells within the bovine and murine cumulus-oocyte complex respectively. Our model differs from others as it: incorporates a term that allows for nonlinear variation of the oxygen consumption rate with oxygen concentration; considers two regions (oocyte and cumulus) sharing a common boundary, both of which consume oxygen at different non linear rates. Cumulus cells therefore remove little $\mathrm{O}_{2}$, thus sparing this essential gas for the oocyte, which is dependent on ATP generation via oxidative phosphorylation.

Reproduction (2006) 131 999-1006
\end{abstract}

\section{Introduction}

A quantitative understanding of nutrient supply to the oocyte in the antral follicle is generally lacking. There is good evidence that, initially, gap-junctional communication between the oocyte and the surrounding cumulus cells is important in nutrient transfer (Herlands \& Shultz 1984), and the transfer of small molecular weight molecules, such as cyclic AMP (Bornslaeger \& Schultz 1985), uridine (Herlands \& Shultz 1984) and glucose (Saito et al. 1994) by this means has been described. Once the gap-junction connection has been severed in response to the ovulatory stimulus (in vivo) or spontaneous meiotic maturation (in vitro), the oocyte presumably relies on a histotrophic nutrient supply, although the close proximity to the expanding cumulus mass is likely to alter nutrient composition adjacent to the oocyte relative to that in the follicular fluid.

One component that appears to be important for the establishment of developmental competence in the oocyte within antral follicles is oxygen. In general, $\mathrm{pO}_{2}$ levels around $7-11 \%$ have been recorded in antral follicles of humans and pigs (Knudsen et al. 1978, Fischer et al. 1992). Several studies in humans (Van Blerkom et al. 1997, Van Blerkom 1998) indicate that perifollicular vascularity is associated with oocyte developmental competence. This was subsequently related to the dissolved $\mathrm{O}_{2}$ content (Van Blerkom 1998), although this association has been disputed (Huey et al. 1999). In contrast, there are many studies that have examined the effect of $\mathrm{O}_{2}$ concentration during in vitro maturation of oocytes across several species. Examples of such studies include hamster (Gwatkin \& Haidri 1974), squirrel monkey (Yeoman et al. 1999), cow (Hashimoto et al. 2000, Minami et al. 2000), pig (Park et al. 2005) and mouse (Haidri et al. 1971, Eppig \& Wigglesworth 1995, Hu et al. 2001). Such studies have not yielded any consensus over the optimal $\mathrm{O}_{2}$ concentration during maturation, as there are conflicting results, especially in regard to the benefits of a low $\mathrm{O}_{2}$ atmosphere. Of central importance to these studies is the choice of oxygen concentration used. Many have compared atmosphere (approximately 20\% $\mathrm{O}_{2}$ ) against $5 \% \quad \mathrm{O}_{2}$ concentrations, the latter being the widely accepted optimal value for the development of mouse embryos in vitro (Quinn \& Harlow 1978).

Recently we measured the uptake of key nutrients in bovine cumulus-oocyte complexes (COCs) to determine if oocyte-secreted factors influence bovine COC metabolism (Sutton et al. 2003). In contrast to the mouse (Sugiura et al. 2005), oocyte-secreted factors appear to have little influence over the metabolism of the surrounding cumulus cells. However, as with the mouse 
(Sugiura et al. 2005), bovine COCs have significant levels of glycolysis, with lactic acid production accounting for much of the glucose taken up, especially prior to cumulus expansion (Sutton et al. 2003). These data suggest that oxygen consumption by the bovine cumulus cell mass is minimal, thus sparing $\mathrm{O}_{2}$ for oxidative phosphorylation by the oocyte. We have therefore developed a mathematical model of the diffusion of oxygen through the COC so as to assess how the $\mathrm{O}_{2}$ concentration decreases from the follicular-fluid cumulus oophorus interface to the corona radiata oocyte interface. We have applied this model to data already described for both bovine and murine COCs.

\section{Materials and Methods}

\section{Cumulus-oocyte complex parameters}

Data for $\mathrm{COC}$ diameter and $\mathrm{O}_{2}$ consumption was obtained from a variety of published sources, identified in Table 1.

\section{General assumptions}

Prior to the luteinising hormone surge, cumulus cells are tightly packed around the oocyte and we have assumed that, in the case of passive diffusion of oxygen, these cumulus cells are effectively a homogeneous mixture of intra- and extracellular matter (Jones 1986). The diffusion coefficient of oxygen in the cumulus mass can therefore be taken to be constant. We have also assumed spherical symmetry of the COC, and ignored that at least part of it is attached to the mural granulosa cell layer of the follicle. The thickness of the zona pellucida (approximately $10 \mu \mathrm{m}$ ) has been neglected, as this is acellular

Table 1 Morphological and oxygen consumption data for bovine and murine cumulus-oocyte complexes. The values for oxygen consumption within oocytes and cumulus cells were calculated from parameters within the table.

\begin{tabular}{|c|c|c|}
\hline & Bovine & Murine \\
\hline \multicolumn{3}{|l|}{ Radius of oocyte $(\mathrm{m})$} \\
\hline Value & $55 \times 10^{-6}$ & $40 \times 10^{-6}$ \\
\hline Reference & Gordon 2003 & Chung 1973 \\
\hline \multicolumn{3}{|l|}{ Radius of COC (m) } \\
\hline Value & $160 \times 10^{-6}$ & $90 \times 10^{-6}$ \\
\hline Reference & $\begin{array}{l}\text { Sutton-McDowall } \\
\text { et al. } 2004\end{array}$ & Downs et al. 1997 \\
\hline \multicolumn{3}{|l|}{ Oocyte $\mathrm{O}_{2}$ uptake $(\mathrm{pl} / \mathrm{h})$} \\
\hline Value & 240 & 140 \\
\hline Reference & $\begin{array}{l}\text { Thompson et al. } \\
1996\end{array}$ & $\begin{array}{l}\text { Houghton et al. } \\
1996\end{array}$ \\
\hline \multicolumn{3}{|l|}{$\mathrm{COC} \mathrm{O}_{2}$ uptake $(\mathrm{pl} / \mathrm{h})$} \\
\hline Value & 1873 & 3780 \\
\hline Reference & Sutton et al. 2003 & Downs et al. 1997 \\
\hline $\begin{array}{l}\text { Oocyte } \mathrm{O}_{2} \text { consumption } \\
\text { (mol/l of tissue/s) }\end{array}$ & $3.8 \times 10^{-6}$ & $5.7 \times 10^{-6}$ \\
\hline $\begin{array}{l}\text { Cumulus cell } \mathrm{O}_{2} \\
\text { consumption (mol/l of } \\
\text { tissue/s) }\end{array}$ & $1.1 \times 10^{-6}$ & $1.4 \times 10^{-5}$ \\
\hline
\end{tabular}

and does not consume oxygen, nor is it likely to impede oxygen diffusion. Finally, we have assumed that the follicular fluid surrounding the COC is perfectly mixed, enabling us to take the concentration of oxygen in this fluid to be constant.

\section{Mathematical model}

The approximate spherical symmetry of the COC and our interest in the very early stage of development justifies our use of a spherically symmetric steady-state model. The rate of oxygen consumption by both oocyte and cumulus is expected to vary with the concentration of oxygen. Thus we solve the equation

$\frac{D}{r^{2}} \frac{d}{d r}\left(r^{2} \frac{d C}{d r}\right)=M(C)$

subject to suitable boundary conditions, for the oxygen concentration $C$ as a function of radial position $r$ from the centre of the COC, where $D$ is the diffusion coefficient and $M(C)$ is the rate of oxygen consumption per unit volume of cells as a function of the concentration $C$.

As the oxygen consumption rate of the oocyte is considerably different to that of the cumulus cells, the COC has been modelled as two spherically symmetric regions. The oxygen consumption rates in the cumulus and oocyte regions are taken to be $M_{1}\left(C_{1}\right)$ and $M_{2}\left(C_{2}\right)$ respectively where $C_{1}, C_{2}$ are the $\mathrm{O}_{2}$ concentrations in each of the regions. The cumulus mass is surrounded by follicular fluid that is assumed to have a known oxygen concentration $C_{f}$.

Thus, the oxygen concentration in the $\mathrm{COC}$ is found by solving two spherically symmetric diffusion equations, one for the cumulus mass yielding $C_{1}$ and the other for the oocyte yielding $C_{2}$ :

$$
\frac{D}{r^{2}} \frac{d}{d r}\left(r^{2} \frac{d C_{1}}{d r}\right)=M_{1}\left(C_{1}\right) \text { for } a<r \leq b
$$

$$
\frac{D}{r^{2}} \frac{d}{d r}\left(r^{2} \frac{d C_{2}}{d r}\right)=M_{2}\left(C_{2}\right) \text { for } 0 \leq r \leq a
$$

where:

$r \quad$ is the radial distance from the centre of the oocyte,

a is the radius of the oocyte,

$b$ is the radius of the COC,

$C_{1}(r)$ is the concentration of oxygen in the cumulus mass,

$C_{2}(r)$ is the concentration of oxygen in the oocyte,

$M_{1}\left(C_{1}\right)$ is the rate of oxygen consumption per unit volume of cumulus mass,

$M_{2}\left(C_{2}\right)$ is the rate of oxygen consumption per unit volume of oocyte. 
At the boundary between the oocyte and the cumulus mass $(r=a)$ we must have continuity of both mass flux and concentration, that is,

$$
\frac{d C_{1}}{d r}(a)=\frac{d C_{2}}{d r}(a)
$$

$C_{1}(a)=C_{2}(a)$.

Also, the concentration must remain bounded at the centre of the COC (as $r \rightarrow 0$ ), or, equivalently for spherical symmetry,

$$
\frac{d C_{2}}{d r}(0)=0
$$

A further condition, on the boundary between the cumulus mass and the follicular fluid $(r=b)$, governs the transport of oxygen into the COC. Here we assume that the flux of oxygen into the cumulus mass is proportional to the difference in oxygen concentration between the cumulus and the surrounding follicular fluid, that is,

$-D \frac{d C_{1}}{d r}(b)=h\left(C_{1}(b)-C_{f}\right)$

where $h$ is the transfer coefficient for this problem.

A common approach to estimating oxygen concentration gradients in the biological literature (e.g. Gosden \& Byatt-Smith 1986, Byatt-Smith et al. 1991) is to solve a diffusion-equation model with the rate of oxygen consumption assumed to be constant or proportional to the oxygen concentration. This assumption allows analytical solution of the governing equations. However, these solutions may be quite inaccurate, and even nonphysical and hence invalid, in some regions of the parameter space, so that care must be exercised when using them. To overcome such difficulties, we have used a functional description of the consumption term that we believe more accurately represents the dependence of oxygen consumption rate on concentration, as we now describe.

In practice, cells consume oxygen at a maximal (or near to maximal) level, until oxygen concentration itself becomes rate limiting. The rate of consumption then falls with concentration, approaching zero as the $\mathrm{O}_{2}$ concentration approaches zero. This behaviour is seen in the curves given in Jones (1984), which show oxygen concentration $\left(\mathrm{O}_{2}\right)$ versus cytochrome-c oxidation (as a measure of consumption rate) in hepatocytes.

A function that captures the general shape of these curves is the Arrhenius law from chemistry,

$M(C)=\beta e^{-\alpha / C}$,

where $\alpha$ and $\beta$ are positive constants. We use this function for the consumption terms in our equations, to relate the rate of oxygen consumption $M$ to the concentration $C$. As $C \rightarrow 0, e^{-\alpha / c} \rightarrow 0$ and, hence, $M(C)$ $\rightarrow 0$, while as $C \rightarrow \infty, e^{-\alpha / C} \rightarrow 1$ and, hence $M(C) \rightarrow \beta$, i.e. $\beta$ is the maximum rate of consumption. The constants $\alpha$ and $\beta$ are chosen to fit appropriate experimental data. This function has the benefit of handling the changing oxygen consumption rate with concentration in a consistent manner for both the cumulus mass and oocyte, but also means that the equations cannot be solved analytically.

Our equations for oxygen transport in the COC are now

$\frac{D}{r^{2}} \frac{d}{d r}\left(r^{2} \frac{d C_{1}}{d r}\right)=\beta e^{-\alpha / C_{1}}$ for $a<r \leq b$,

$\frac{D}{r^{2}} \frac{d}{d r}\left(r^{2} \frac{d C_{2}}{d r}\right)=\gamma e^{-\delta / C_{2}}$ for $0 \leq r \leq a$,

where $\alpha, \beta, \gamma$ and $\delta$ are positive constants. We have allowed that the constants in the consumption term may differ between the cumulus mass $(\alpha, \beta)$ and the oocyte $(\gamma, \delta)$. While not solvable analytically, this system of equations, together with the associated boundary conditions described earlier, is readily solved numerically using, for example, MATLAB (Version 6.5, 2002, The Mathworks Inc.).

\section{Results}

\section{Estimation of model parameters from experimental data}

Estimates of model parameters for cow and mouse were made using data from a variety of published sources (Table 1). In particular, using data on the size and total oxygen consumption by oocyte and COC, the maximum rate of oxygen consumption in moles (mol) per litre (I) of tissue per second (s) was computed thus: for a maximum oxygen uptake $U$ picolitres per hour $(\mathrm{pl} / \mathrm{h})$ by a cell volume $V$ cubic metres, the maximum oxygen consumption rate in mol per litre of tissue per second is given by

$$
\frac{U \times 10^{-12}}{V \times 1000 \times 25.4 \times 3600} \text {. }
$$

Here we have assumed oxygen to be an ideal gas so that the volume of a mole of oxygen at $37^{\circ} \mathrm{C}$ is 25.4 litres. For the oocyte the uptake is as given in Table 1 ; for the cumulus it is the difference between that for the COC and that for the oocyte, i.e. $1873-240=1633 \mathrm{pl} / \mathrm{h}$. The volume of the oocyte is given by $V=4 \pi a^{3} / 3$, where $a$ is its radius in metres; the volume of the cumulus is $V=4 \pi\left(b^{3}-a^{3}\right) / 3$, where $b$ is the radius of the COC in metres. The results of these calculations are shown in the bottom two rows of Table 1 . It can be seen that a bovine oocyte consumes 3.5 times as much $\mathrm{O}_{2}$ per unit volume of tissue per unit time than the surrounding cumulus cell 
mass. In murine COCs this is reversed, with the cumulus cell mass consuming 2.4 times as much as the oocyte (per unit volume per unit time).

We set $\beta$ to be the maximum rate of oxygen consumption by the cumulus mass (per unit volume per unit time), as given in Table 1 for each of cow and mouse. Since the consumption in a bovine (murine) oocyte is approximately $3.5(0.4)$ times that in the cumulus (see Table 1), we take $\gamma=3.5 \beta$ and $\gamma=0.4 \beta$ for each of cow and mouse respectively.

The parameters $\alpha$ and $\delta$ in the consumption-rate terms determine the dependence of consumption rate on oxygen concentration, i.e. they are effectively measures of the half-maximal oxidation $\mathrm{P}_{50}$ value in the cumulus and oocyte respectively. We obtain estimates for these parameters by assuming, in the absence of specific data for the oocyte and cumulus, that they behave similarly to hepatocyte cells, and fitting the Arrhenius consumptionrate term to experimental data given in Jones (1984) which relates the rate of oxygen consumption to oxygen concentration for both untreated and digitonin-treated hepatocytes; digitonin-treated hepatocytes are shown to be less $\mathrm{O}_{2}$-dependent than untreated (intact) cells, with a $\mathrm{P}_{50}$ of about $2 \mu \mathrm{mol} \mathrm{L}{ }^{-1}$ compared to $6 \mu \mathrm{mol} \mathrm{L}^{-1}$. The acellular oocyte can be expected to have similar $\mathrm{O}_{2}$ dependence to digitonin-treated hepatocytes. Physiologically, the cumulus is likely to have a lower respiratory rate and, consequently, lower $\mathrm{O}_{2}$ dependence than (untreated) hepatocytes; however, due to its cellular structure, the cumulus mass is likely to have greater $\mathrm{O}_{2}$ dependence than digitonin-treated hepatocytes. Thus, the correct relation for the cumulus is expected to lie between these two curves, which may therefore be considered as limiting cases; intermediate cases may be obtained by varying the $P_{50}$ value between that for digitonin-treated and that for untreated hepatocytes. In fact, the oxygen concentrations in the oocyte are lowest under the assumption that the cumulus has an $\mathrm{O}_{2}$ dependence equal to digitonin-treated hepatocytes; as the $\mathrm{P}_{50}$ increases towards that for untreated hepatocytes, the concentration gradient across the COC decreases and oxygen concentrations in the oocyte increase because the cumulus mass consumes less oxygen. Therefore we have adopted the curve for digitonin-treated hepatocytes to represent the $\mathrm{O}_{2}$ dependence of the cumulus as the 'worst-case' scenario in the sense that oxygen concentrations are not overestimated.

Thus, we use the curve for digitonin-treated hepatocytes in Jones (1984) to give the $\mathrm{O}_{2}$ dependence for both the cumulus and oocyte (i.e. the values of $\alpha$ and $\delta$ in the consumption-rate terms of the model). With $P_{50} \approx 2 \mu \mathrm{mol} \mathrm{L}{ }^{-1}$, the half-maximal consumption rate for the cumulus $(\beta / 2)$ is given by the Arrhenius law thus:

$\frac{\beta}{2}=\beta e^{-\alpha / 2 \times 10^{-6}}$
Dividing through by $\beta$ and rearranging gives:

$$
\begin{aligned}
& 2=e^{\alpha / 2 \times 10^{-6}} \Rightarrow \frac{\alpha}{2} \times 10^{6}=\ln (2) \\
& \Rightarrow \quad \alpha=2 \ln (2) \times 10^{-6}=1.39 \times 10^{-6} \mathrm{~mol} \mathrm{~L}^{-1} .
\end{aligned}
$$

Thus we set $\alpha=\delta=1.39 \times 10^{-6} \mathrm{~mol} \mathrm{~L}^{-1}$ for both cow and mouse COCs.

As discussed later, because oxygen diffuses readily through cellular material and consumption terms for both the cumulus mass and the oocyte are specifically included in our equations, the appropriate diffusion coefficient is that of oxygen in physiological saline, i.e. $D=2.5 \times 10^{-9} \mathrm{~m}^{2} \mathrm{~s}^{-1}$, Jones (1984). The transfer coefficient $h$ is a measure of the impedance to oxygen transport provided by the boundary between the follicular fluid and the cumulus mass; the higher the value, the lower the impedance. Because our model assumes the cumulus mass to be a homogeneous mixture of intra- and extracellular materials, there is no physical membrane boundary separating the cumulus mass from the follicular fluid and we expect little, if any, resistance to oxygen transport into the cumulus mass. Numerical experiments over a range of values of $h$ revealed that there was little impedance for $h>1$, effectively equivalent to setting the $\mathrm{O}_{2}$ concentration at the boundary equal to the concentration in the follicular fluid (i.e. $C(b)=C_{f}$ ) and we have chosen to use a value of $h=10 \mathrm{~m} / \mathrm{s}$. A summary of the parameter values used in our equations is given in Table 2 .

The concentration of oxygen in the surrounding fluid $\left(C_{f}\right)$ has a typical value (in vivo) of around $11 \%$ partial pressure (Knudsen et al. 1978, Fischer et al. 1992). However, our computations have been done for $C_{f}$ in the range $3-20 \%$ in order to explore how the oxygen concentration in the follicular fluid affects concentrations in the COC. Concentrations in units of mole per litre $(\mathrm{mol} / \mathrm{l})$ for use in our model are found from $1 \%$ $\mathrm{O}_{2}=7.6 \mathrm{mmHg}$ at sea level and the relationship:

$$
\begin{aligned}
& \text { Concentration of gas in a liquid }\left(\mathrm{mol} \mathrm{L}^{-1}\right) \\
& =\text { Solubility }\left(\mathrm{mol} \mathrm{L}^{-1} \mathrm{~mm} \mathrm{Hg}^{-1}\right) \times \text { Pressure }(\mathrm{mmHg})
\end{aligned}
$$

where solubility is taken to be $1.2 \times 10^{-6} \mathrm{~mol} / \mathrm{l}$ per $\mathrm{mmHg}$.

Table 2 Parameters used for bovine and murine cumulus-oocyte complex.

\begin{tabular}{lccl}
\hline Parameter & Bovine value & Murine value & Units \\
\hline$a$ & $55 \times 10^{-6}$ & $40 \times 10^{-6}$ & $\mathrm{~m}$ \\
$b$ & $160 \times 10^{-6}$ & $90 \times 10^{-6}$ & $\mathrm{~m}$ \\
$\beta$ & $1.1 \times 10^{-6}$ & $1.43 \times 10^{-6}$ & $\mathrm{~mol} / \mathrm{/} / \mathrm{s}$ \\
$\gamma$ & $3.5 \beta$ & $0.4 \beta$ & $\mathrm{mol} / / \mathrm{s}$ \\
$\alpha, \delta$ & $1.39 \times 10^{-6}$ & $1.39 \times 10^{-6}$ & $\mathrm{~mol} / \mathrm{l}$ \\
$D$ & $2.5 \times 10^{-9}$ & $2.5 \times 10^{-9}$ & $\mathrm{~m}{ }^{2 /} \mathrm{s}$ \\
$h$ & 10 & 10 & $\mathrm{M} / \mathrm{s}$ \\
\hline
\end{tabular}




\section{Oxygen concentration: solutions}

The governing equations were solved using MATLAB for each of two sets of parameters (for cow and mouse), and varying the oxygen concentration $C_{f}$ in the surrounding fluid. Figure 1 shows the oxygen concentration gradient across a bovine COC when the oxygen concentration in the follicular fluid is at $10 \%$. The shape of the curve is typical of other values also. Figure 2 shows the change in oxygen concentration with radius in the bovine cumulus mass only for a number of values of $C_{f}$ and Table 3 gives the oxygen concentration at the oocyte-cumulus boundary, for various values of $C_{f}$. As can be seen, there is a relatively small concentration gradient across the cumulus radius indicating that, in preovulatory antral follicles, a relatively small amount of the oxygen entering the COC is actually consumed by the cumulus mass, with the majority diffusing through to the oocyte.

Figure 3 and Table 3 give similar results for the murine COC. Even though the relative proportion of oxygen consumed per unit volume of cumulus mass is higher in a murine COC than a bovine, there is still very little (maximally approximately $0.5 \% \mathrm{O}_{2}$ ) consumed by the cumulus mass, because the cumulus volume is smaller than that of the oocyte.

\section{Discussion}

Diffusion models are appropriate for estimating concentration gradients in many cellular systems. Early onedimensional steady-state models are found in Krogh (1919) and Warburg (1923). Krogh (1919) considered oxygen diffusion from a cylindrical capillary into the surrounding tissue; oxygen concentration was assumed to be independent of distance along the axis of the

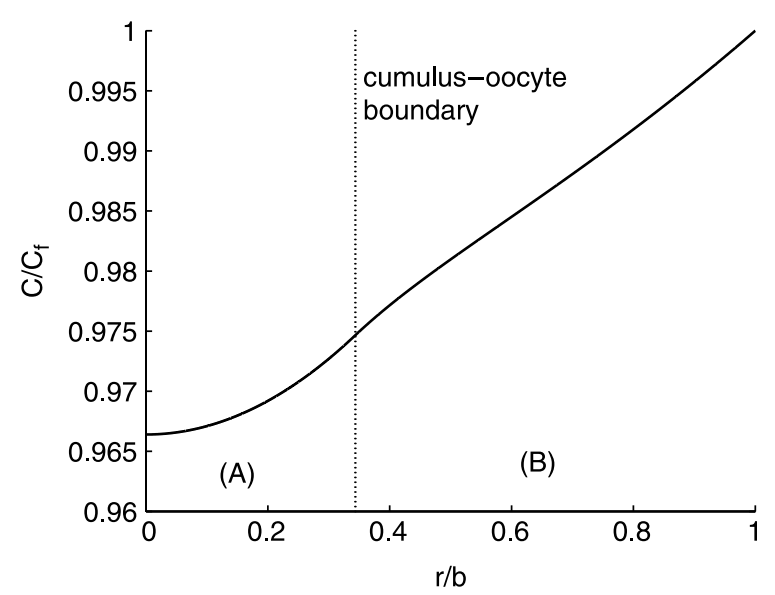

Figure $1 \mathrm{O}_{2}$ concentration $C / C_{f}$ versus radius $r / b$ in the bovine cumulus-oocyte complex for an oxygen concentration $C_{f}=10 \%$ in the surrounding follicular fluid. (A) Oocyte region, (B) cumulus region. The dotted line denotes the boundary between the cumulus mass and the oocyte.

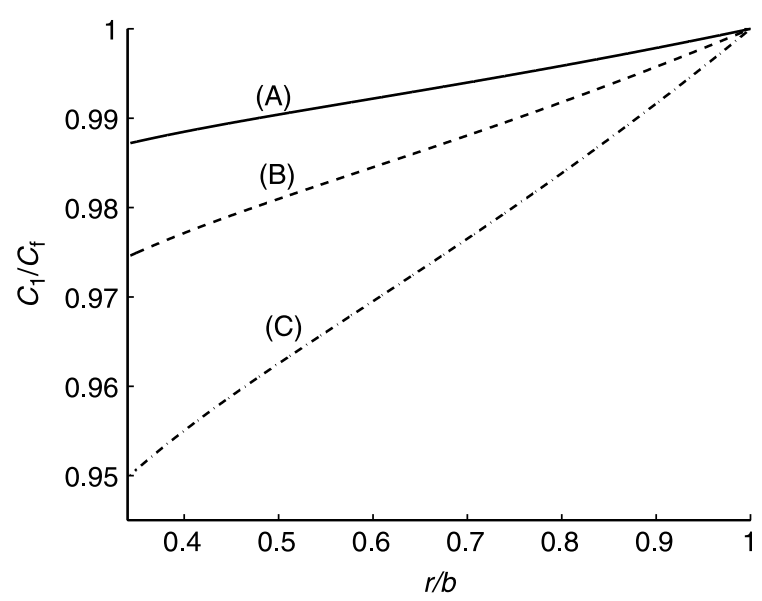

Figure $2 \mathrm{O}_{2}$ concentration $C_{1} / C_{f}$ versus radius $r / b$ in the bovine cumulus mass for various concentrations of oxygen in the surrounding follicular fluid: (A) $C_{f}=20 \%$, (B) $C_{f}=10 \%$ and (C) $C_{f}=5 \%$.

capillary and angular position and, hence, to vary only with radial distance from the capillary wall. Warburg's (1923) model assumes that concentration is constant in a plane and varies in the direction normal to the plane. More recently, the spherically symmetric form of the steady-state diffusion equation has been employed for modelling oxygen concentrations in ovarian follicles (Gosden \& Byatt-Smith 1986) and in preimplantation embryos in static culture (Byatt-Smith et al. 1991).

Our model also assumes spherical symmetry, but differs from previous work in that we have incorporated a term that allows for nonlinear variation of the oxygen consumption rate with oxygen concentration in a manner that fits experimental data. Previous studies (Gosden \& Byatt-Smith 1986, Byatt-Smith et al. 1991) consider the cases of constant rate of oxygen consumption and consumption rate proportional to concentration, which fail to give accurate solutions at low and high oxygen concentrations respectively. Gielen \& Kranenbarg (2002) combined these two cases when

Table 3 The concentration of $\mathrm{O}_{2}$ at the surface of a bovine and murine oocyte for various values of $\mathrm{O}_{2}$ concentration in the surrounding follicular fluid.

\begin{tabular}{|c|c|c|c|c|}
\hline $\begin{array}{l}\% \mathrm{O}_{2} \text { in } \\
\text { follicular } \\
\text { fluid } C_{f}\end{array}$ & $\begin{array}{c}\text { Proportion } \\
\text { at bovine } \\
\text { oocyte } \\
C_{1}\left(\text { a) } / C_{f}\right.\end{array}$ & $\begin{array}{c}\% \mathrm{O}_{2} \text { at } \\
\text { bovine } \\
\text { oocyte- } \\
\text { cumulus } \\
\text { boundary } \\
r=a\end{array}$ & $\begin{array}{c}\text { Proportion } \\
\text { at murine } \\
\text { oocyte } \\
C_{1} \text { (a) } / C_{f}\end{array}$ & $\begin{array}{c}\% \mathrm{O}_{2} \text { at } \\
\text { murine } \\
\text { oocyte- } \\
\text { cumulus } \\
\text { boundary } \\
r=a\end{array}$ \\
\hline 20 & 0.987 & 19.74 & 0.972 & 19.44 \\
\hline 10 & 0.975 & 9.75 & 0.944 & 9.44 \\
\hline 7 & 0.964 & 6.75 & 0.921 & 6.45 \\
\hline 6 & 0.958 & 5.75 & 0.908 & 5.45 \\
\hline 5 & 0.950 & 4.75 & 0.890 & 4.45 \\
\hline 4 & 0.938 & 3.75 & 0.864 & 3.46 \\
\hline 3 & 0.919 & 2.76 & 0.822 & 2.47 \\
\hline
\end{tabular}




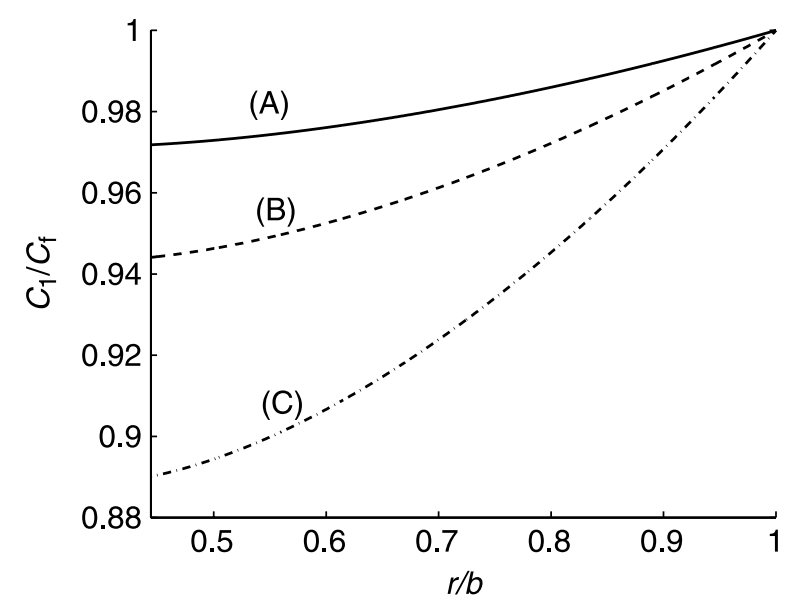

Figure $3 \mathrm{O}_{2}$ concentration $C_{1} / C_{f}$ versus radius $r / b$ in the murine cumulus mass for various concentrations of oxygen in the surrounding follicular fluid: (A) $C_{f}=20 \%$, (B) $C_{f}=10 \%$ and (C) $C_{f}=5 \%$.

considering oxygen diffusion in small organisms; $\mathrm{O}_{2}$ consumption was taken to be piecewise linear-constant at high $\mathrm{O}_{2}$ concentrations, and proportional to concentration below some threshold $\mathrm{O}_{2}$ concentration. This is more accurate, but requires that the boundary between regions of high and low $\mathrm{O}_{2}$ concentration be determined (e.g. by solving a complex transcendental equation). By introducing a nonlinear term to represent the rate of oxygen consumption as a function of $\mathrm{O}_{2}$ concentration, we eliminate the need to determine regions of high and low concentration and have constructed a model that can be better fitted to experimental data and hence should be more accurate over the entire range of possible oxygen concentrations.

Our model also differs from these previous similar studies in considering two regions (oocyte and cumulus) sharing a common boundary, both of which consume oxygen at different nonlinear rates. Multi-compartment models can be found in the literature to represent nutrient diffusion in other biological systems (for example Hoofd et al. 1990, Bruggeman et al. 2001, Kumar et al. 2004) but have not been applied to cumulus-oocyte complex systems.

Our results for both cow and mouse show a small concentration gradient from the follicular fluid across the cumulus mass to the oocyte, and hence demonstrate that only a small fraction of the oxygen entering the COC system is consumed by the cumulus mass during diffusion across the cumulus layer. Thus the level of oxygen at the surface of the oocyte is approximately $5-15 \%$ lower than that in the follicular fluid, depending on $\mathrm{O}_{2}$ concentration and metabolic activity of cumulus cells between species. However, this result is sensitive to the value of the diffusion coefficient $D$ for oxygen across the oocyte-cumulus complex.

There has been much discussion in the literature on the appropriate value of the oxygen diffusion coefficient for a medium consisting largely of intracellular matter/ fluid (Hills 1970, Tai \& Chang 1974, Jones \& Kennedy 1982, Jones 1986, McCabe et al. 2003). Values ranging from that for pure water at $37^{\circ} \mathrm{C}\left(D_{w}=2.5 \times 10^{-9} \mathrm{~m}^{2} / \mathrm{s}\right)$ to 3 orders of magnitude smaller have been used. For example, Gosden \& Byatt-Smith (1986) used a value of $7 \times 10^{-12} \mathrm{~m}^{2} / \mathrm{s}$, but later (Byatt-Smith et al. 1991) considered $D_{w}$ as well as values 5-10 times smaller. Our review of the literature leads us to conclude that values of the diffusion coefficient differing significantly from $D_{w}$ are due to assumptions made in deriving the models used to determine the diffusion coefficient from experimental data, as well as error in experimental measurement. For example, the common neglect of oxygen consumption by some parts of a biological system will result in a low apparent diffusion coefficient. We note that Jones (1986), commenting on a diffusion coefficient $\sim D_{w} / 70$, states that that "no physical or chemical basis is known to account for such a low value in cells". Jones (1986) also quotes experimental studies that indicate a value $\sim 10^{-9} \mathrm{~m}^{2} \mathrm{~s}^{-1}$ for the diffusion coefficient of oxygen in tissue, which corresponds to $D_{w}$. Recently, McCabe et al. (2003) discussed the experimental evidence for enhanced oxygen diffusion in respiring tissue, such as in a COC, and quote a diffusivity of $D=3 \times 10^{-9} \mathrm{~m}^{2} \mathrm{~s}^{-1}$ for liver cells. This is not significantly different (only 1.2 times) to the value in water used here. An even more recent study of oxygen levels in a very different system, the mammalian ocular lens containing closely packed fibre cells (McNulty et al. 2004), finds a diffusion coefficient "indistinguishable from that of oxygen in water" using a spherically symmetric diffusion model including consumption. Since our model includes specific terms for all oxygen consumption by both cumulus mass and oocyte, we conclude that the value of the diffusion coefficient appropriate to our model is that for oxygen diffusion in pure water at $37^{\circ} \mathrm{C}$, which is also the value quoted for oxygen diffusion in physiological saline.

The significance of our results should have impact in several areas of oocyte biology and maturation. First, as already mentioned, in studying $\mathrm{O}_{2}$ diffusion across a preantral follicle, Gosden \& Byatt-Smith (1986), with reference to Jones and Kennedy (1982), used a diffusion coefficient of $7 \times 10^{-12} \mathrm{~m}^{2} / \mathrm{s}$, almost 3 orders of magnitude smaller than that of $\mathrm{O}_{2}$ in water. This results in a considerably steeper concentration gradient across the oocyte-granulosa cell complex, and hence a much lower oxygen concentration at the oocyte-granulosa cell boundary, than is obtained using the diffusion coefficient for $\mathrm{O}_{2}$ in water (data not shown). The small diffusion coefficient was, in fact, obtained by comparing experimental data for rat hepatocytes with predictions from a model that assumes no oxygen consumption in a rat hepatocyte excepting for that by an isolated mitochondrion at the centre of the cell (see Jones \& Kennedy, 1982). This will result in a significant underestimation of 
the diffusion coefficient and, consequently, low predictions of oxygen concentrations from models that use it. Hence, the results from Gosden \& Byatt-Smith (1986), which suggest that the developing oocyte in the preantral follicle is certainly anoxic, should be reviewed.

Secondly, there is no consensus as to the optimal $\mathrm{O}_{2}$ concentration for in vitro maturation of oocytes. The early embryo appears to be sensitive to either atmospheric or hypoxic $\mathrm{O}_{2}$ levels in several mammalian species, resulting in decreased development (e.g. Thompson et al. 1990). Intermediate concentrations of $\mathrm{O}_{2}$, which appear to approximate in vivo concentrations, are beneficial for development (Harvey et al. 2002). Therefore, it seems likely that $\mathrm{O}_{2}$ levels for in vitro maturation should follow a similar trend, in that levels approximating in vitro concentrations would be more likely to be beneficial for oocyte maturation, rather than the majority current practise of the use of atmospheric levels. Recently, Hashimoto et al. (2000) demonstrated that for in vitro maturation of bovine oocytes in the presence of $20 \mathrm{mM}$ glucose, $5 \% \mathrm{O}_{2}$ during maturation yielded more blastocyst-stage embryos than $20 \% \mathrm{O}_{2}$. This also correlated with a reduction in the intra-oocyte level of reactive oxygen species. The relatively high glucose level was required to overcome deficiencies in meiotic maturation, which are glucose concentrationdependent during in vitro maturation (Sutton-McDowell et al. 2005). Such changes in substrate concentration may alter oxygen consumption rates by the COC. However, we believe that such changes would lead to only small deviations in oxygen uptake, as many more molecules of substrates such as pyruvate and glucose are oxidised for every additional molecule of oxygen consumed.

One critical assumption made for our mathematical model is that the COC is close to spherical. This is clearly not the case, where a "stalk" of granulosa cells fixes the cumulus mass to the membrana granulosa. Around this region, one would expect the $\mathrm{O}_{2}$ concentration at the surface of the oocyte to be less than indicated by the values given in this paper, allowing the establishment of a polarised $\mathrm{O}_{2}$ concentration around the oocyte. Whether or not such a gradient has physiological relevance is unknown, although the concept of localised intracellular ATP production and polarity in mitochondrial distribution is clearly discussed in the literature (e.g. for review, see Van Blerkom 2004).

In conclusion, we have developed a mathematical model to describe the perfusion of oxygen across the COC. This model reveals that follicle lumen concentrations of oxygen most likely reflect what is seen by the oocyte itself. Although it is known that the cumulus-free oocyte is dependent on oxidative phosphorylation for developmental competency (Van Blerkom et al. 1995), dependency of the oocyte on its own mitochondrial activity during maturation, especially when significant cell-communication occurs via gap junctions with the cumulus layer, is unknown (Van Blerkom 2004). However, even if oxygen consumption by the oocyte is less than the values utilised here, the gradient of $\mathrm{O}_{2}$ would be even less than our current model predicts. Overall, we believe our model makes physiological sense and therefore may be useful in determining the sensitivity of maturing COCs to different oxygen concentrations. Furthermore, our model can also be applied to other questions relating to diffusion of molecules across spherical structures occurring within reproduction, such as follicles and early embryos.

\section{Acknowledgements}

ARC is supported by a University of Adelaide scholarship (Adelaide Scholarships International, ASI). This work was partially supported by NIH as part of the NICHD National Cooperative Program on Female Health and Egg Quality under cooperative agreement U01 HD044644. The authors are thankful for some helpful comments from Dr S. Cox (Applied Mathematics, The University of Adelaide).

\section{References}

Bornslaeger EA \& Schultz RM 1985 Adenylate cyclase activity in zonafree mouse oocytes. Experimental Cell Research 156 277-281.

Bruggeman FJ, Libbenga KR \& Van Darjn B 2001 The diffusive transport of gibberillins and abscisic acid through the aleurone layer of germinating barley grain: a mathematical model. Planta 214 89-96.

Byatt-Smith JG, Leese HJ \& Gosden RG 1991 An investigation by mathematical modelling of whether mouse and human preimplantation embryos in static culture can satisfy their demands for oxygen by diffusion. Human Reproduction 6 52-57.

Chung SO 1973 Volume changes during the preimplantation stages of mouse egg development. Yonsei Medical Journal 14 63-90.

Downs SM, Houghton FD, Humpherson PG \& Leese HJ 1997 Substrate utilization and maturation of cumulus cell-enclosed mouse oocytes: Evidence that pyruvate oxidation does not mediate meiotic induction. Journal of Reproduction and Fertility 110 1-10.

Eppig JJ \& Wigglesworth K 1995 Factors affecting the developmental competence of mouse oocytes grown in vitro: Oxygen concentration. Molecular Reproduction and Development 42 447-456.

Fischer B, Kunzel W, Kleinstein J \& Gips H 1992 Oxygen tension in follicular fluid falls with follicle maturation. European Journal of Obstetrics \& Gynaecology and Reproductive Biology 43 39-43.

Gielen JLW \& Kranenbarg S 2002 Oxygen balance for small organisms: an analytical model. Bulletin of Mathematical Biology 64 175-207.

Gordon I 2003 Laboratory production of cattle embryos, $2^{\text {nd }}$ Ed. Oxon, UK: CABI Publishing.

Gosden RG \& Byatt-Smith JG 1986 Oxygen concentration gradient across the ovarian follicular epithelium: model, predictions and implications. Human Reproduction 1 65-68.

Gwatkin RBL \& Haidri AA 1974 Oxygen requirements for the maturation of hamster oocytes. Journal of Reproduction and Fertility 37 127-129.

Haidri AA, Miller IM \& Gwatkin RBL 1971 Culture of mouse oocytes in-vitro, using a system without oil or protein. Journal of Reproduction and Fertility 26 409-411.

Harvey AJ, Kind KL \& Thompson JG 2002 Redox regulation of early embryo development. Reproduction 123 479-486.

Hashimoto S, Minami N, Takakura R, Yamada M, Imai H \& Kashima N 2000 Low oxygen tension during in vitro maturation is beneficial for 
supporting the subsequent development of bovine cumulus-oocyte complexes. Molecular Reproduction and Development 57 353-360.

Herlands RL \& Shultz RM 1984 Regulation of mouse oocytes growth: Probable nutritional role for intercellular communication between follicle cells and oocyte growth. Journal of Experimental Zoology 229 317-325.

Hills BA 1970 Respiration of tissue as a medium of heterogeneous permeability. The Bulletin of Mathematical Biophysics 32 219-235.

Hoofd L, Turek Z \& Egginton S 1990 Concentric oxygen diffusion in tissue with heterogeneous permeability and consumption. Advances in Experimental Medicine and Biology 277 13-20.

Houghton FD, Thompson JG, Kennedy CJ \& Leese HJ 1996 Oxygen consumption and energy metabolism of the early mouse embryo. Molecular Reproduction and Development 44 476-485.

Hu Y, Betzendahl L, Cortvrindt R, Smitz J \& Eichenlaub-Ritter U 2001 Effects of low $\mathrm{O}_{2}$ and ageing on spindles and chromosomes in mouse oocytes from pre-antral follicle culture. Human Reproduction $\mathbf{1 6}$ 737-748.

Huey S, Abuhamad A, Barroso G, Hsu MI, Kolm P, Mayer J \& Oehninger S 1999 Perifollicular blood flow doppler indices, but not follicular $\mathrm{pO}_{2}, \mathrm{pCO}_{2}$, or $\mathrm{pH}$, predict oocyte developmental competence in in vitro fertilization. Fertility and Sterility 72 707-1055.

Jones DP 1984 Effect of mitochondrial clustering on $\mathrm{O}_{2}$ supply in hepatocytes. American Journal of Physiology; Cell Physiology 247 C83-C89.

Jones DP 1986 Intracellular diffusion gradients of $\mathrm{O}_{2}$ and ATP. American Journal of Physiology; Cell Physiology 250 C663-C675.

Jones DP \& Kennedy FG 1982 Intracellular oxygen supply during hypoxia. American Journal of Physiology; Cell Physiology 243 C247-C253.

Knudsen JF, Litkowski LJ, Wilson TL, Guthrie HD \& Batta SK 1978 Concentrations of hydrogen ions, oxygen, carbon dioxide and bicarbonate in porcine follicular fluid. Journal of Endocrinology $\mathbf{7 9}$ 249-250.

Krogh A 1919 The number and distribution of capillaries in muscles with calculations of the oxygen pressure head necessary for supplying the tissue. Journal of Physiology 52 409-415.

Kumar R, Stepanek F \& Mantalaris A 2004 An oxygen transport model for human bone marrow microcirculation. Food and Bioproducts 82 (C2) 105-116.

McNulty R, Wang H, Mathias RT, Ortwerth BJ, Truscott RJW \& Bassnett S 2004 Regulation of tissue oxygen levels in the mammalian lens. Journal of Physiology 559 883-898.

Minami HS, Takakura R, Yamada M, Imai H \& Kashima N 2000 Low oxygen tension during in vitro maturation is beneficial for supporting the subsequent development of bovine cumulus-oocyte complexes. Molecular Reproduction and Development 57 353-360.

Park JI, Hong JY, Hong HY, Hwang WS, Lim JM \& Lee ES 2005 High oxygen tension during in vitro oocyte maturation improves in vitro development of porcine oocytes after fertilization. Animal Reproduction Science 87 133-141.

Quinn P \& Harlow GM 1978 The effect of oxygen on the development of preimplantation mouse embryos in vitro. Journal of Experimental Zoology 206 73-80.
Saito T, Hiroi M \& Kato T 1994 Development of glucose utilization studied in single oocytes and preimplantation embryos from mice. Biology of Reproduction 50 266-270.

Sugiura K, Pendola FL \& Eppig JJ 2005 Oocyte control of metabolic cooperativity between oocytes and companion granulosa cells: Energy metabolism. Developmental Biology 279 20-30.

Sutton ML, Cetica PD, Beconi MT, Kind KL, Gilchrist RB \& Thompson JG 2003 Influence of oocyte-secreted factors and culture duration on the metabolic activity of bovine cumulus cell complexes. Reproduction 126 27-34.

Sutton-McDowall ML, Gilchrist RB \& Thompson JG 2004 Cumulus expansion and glucose utilisation by bovine cumulus-oocyte complexes during in vitro maturation: The influence of glucosamine and follicle-stimulating hormone. Reproduction 128 314-319.

Sutton-McDowall ML, Gilchrist RB \& Thompson JG 2005 Effect of hexoses and gonadotrophin supplementation on bovine oocyte nuclear maturation during in vitro maturation in a synthetic follicle fluid medium. Reproduction, Fertility and Development $\mathbf{1 7}$ 407-415.

Tai RC \& Chang H 1974 Oxygen transport in heterogeneous tissue. Journal of Theoretical Biology 43 265-276.

Thompson JG, Simpson AC, Pugh PA, Donnelly PE \& Tervit HR 1990 Effect of oxygen concentration on in-vitro development of preimplantation sheep and cattle embryos. Journal of Reproduction and Fertility 89 573-578.

Thompson JG, Partridge RJ, Houghton FD, Cox CI \& Leese HJ 1996 Oxygen uptake and carbohydrate metabolism by in vitro derived bovine embryos. Journal of Reproduction and Fertility 106 299-306.

Van Blerkom J 1998 Epigenetic influences in oocyte developmental competence: Perifollicular vascularity and intrafollicular oxygen. Journal of Assisted Reproduction and Genetics 15 226-234.

Van Blerkom J 2004 Mitochondria in human oogenesis and preimplantation embryogenesis: Engines of metabolism, ionic regulation and developmental competence. Reproduction 128 269-280.

Van Blerkom J, Davis PW \& Lee J 1995 ATP content of human oocytes and developmental potential and outcome after in-vitro fertilization and embryo transfer. Human Reproduction 10 415-424.

Van Blerkom J, Antczak M \& Schrader R 1997 The developmental potential of the human oocyte is related to the dissolved oxygen content of follicular fluid: Association with vascular endothelial growth factor levels and perifollicular blood flow characteristics. Human Reproduction 12 1047-1055.

Warburg O 1923 Versuche an uberlebendum carcinomgewebe. Biochemische Zeitschrift 142 317-333.

Yeoman RR, Williams LE \& Abee CR 1999 Low oxygen inhibits but complex high-glucose medium facilitates maturation of squirrel monkey oocyte-granulosa cell complexes. Journal of Assisted Reproduction and Genetics 16 102-107.

Received 20 September 2005

First decision 17 November 2005

Revised manuscript received 14 December 2005

Accepted 21 February 2006 